\title{
Functional homogeneous zones (fHZs) in viticultural zoning procedure: an Italian case study on Aglianico vine
}

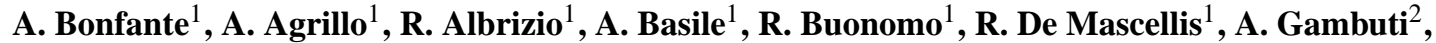 \\ P. Giorio ${ }^{1}$, G. Guida ${ }^{1}$, G. Langella ${ }^{1}$, P. Manna ${ }^{1}$, L. Minieri ${ }^{2}$, L. Moio ${ }^{2}$, T. Siani ${ }^{2}$, and F. Terribile ${ }^{2}$ \\ ${ }^{1}$ National Research Council of Italy (CNR), Institute for Mediterranean Agricultural and Forestry Systems \\ (ISAFOM), Ercolano (NA), Italy \\ ${ }^{2}$ University of Naples Federico II, Department of Agriculture, Portici (NA), Italy
}

Correspondence to: A. Bonfante (antonello.bonfante@cnr.it)

Received: 28 October 2014 - Published in SOIL Discuss.: 17 December 2014

Revised: 3 May 2015 - Accepted: 22 May 2015 - Published: 9 June 2015

\begin{abstract}
This paper aims to test a new physically oriented approach to viticulture zoning at farm scale that is strongly rooted in hydropedology and aims to achieve a better use of environmental features with respect to plant requirements and wine production. The physics of our approach are defined by the use of soil-plant-atmosphere simulation models, applying physically based equations to describe the soil hydrological processes and solve soil-plant water status.

This study (part of the ZOVISA project) was conducted on a farm devoted to production of high-quality wines (Aglianico DOC), located in southern Italy (Campania region, Mirabella Eclano, AV). The soil spatial distribution was obtained after standard soil survey informed by geophysical survey. Two homogeneous zones (HZs) were identified; in each one a physically based model was applied to solve the soil water balance and estimate the soil functional behaviour (crop water stress index, CWSI) defining the functional homogeneous zones (fHZs). For the second process, experimental plots were established and monitored for investigating soil-plant water status, crop development (biometric and physiological parameters) and daily climate variables (temperature, solar radiation, rainfall, wind).

The effects of crop water status on crop response over must and wine quality were then evaluated in the fHZs. This was performed by comparing crop water stress with (i) crop physiological measurement (leaf gas exchange, chlorophyll $a$ fluorescence, leaf water potential, chlorophyll content, leaf area index (LAI) measurement), (ii) grape bunches measurements (berry weight, sugar content, titratable acidity, etc.) and (iii) wine quality (aromatic response). This experiment proved the usefulness of the physically based approach, also in the case of mapping viticulture microzoning.
\end{abstract}

\section{Introduction}

Concepts such as terroir and viticulture zoning are becoming increasingly more important for planning and managing vineyards aiming at high-quality wine (Gladstones and Smart, 1997; Carey, 2001; Vaudour, 2003). Briefly, their practical implementation (Deloire et al., 2005; Fregoni, 1988) aims to classify the landscape (mainly climate and soil), studying its interaction with vineyard and wine quality. Mapping of terroir and viticulture zoning have been devel- oped at all scales, especially since the 1990s following the widespread use of geomatics (Girard and Girard, 2003).

The methodology (even if not unique) not only gave many positive results but also showed some important limitations, mainly related to its strongly empirical base. In other words the terroir is a sort of "black box" in which the quantitative linkage between climate-soil-plant system and wine is empirically or statistically described (e.g. Brousset et al., 2010) and not analysed with regard to its mechanics (Bonfante et al., 2011). 
Recently, some changes have been made and the spatial analysis of terroirs has improved, incorporating some key features known to strongly affect wine quality. Among them are solar radiation and bioclimatic indexes (Failla et al., 2004; Vaudour, 2001) as well as morphometric data and multitemporal remotely sensed images (Vaudour et al., 2010).

Moreover, Bonfante et al. (2011) demonstrated that terroir analysis - applied at a district scale (mesoscale sensu Vaudour and Shaw, 2005) - can become more profitable by combining high-quality GIS (as bioclimatic indexes) with water balance simulation modelling for addressing the key and very complex issue of soil-plant water stress. This is very important because, even if it is well known that water stress strongly affects grape quality, its spatial description can be a very difficult issue.

Despite this result, it is still very questionable whether a similar approach can be usefully applied at a more local less aggregated - spatial scale where ecophysiological functioning and land management play a key role. Moreover, this detailed scale is very useful because it makes it possible to evaluate the functional relationships between viticulture zones, plant-soil water stress, vineyard status and grape wine quality.

To address this issue here we refer to "microzoning" in coherence with the term "microscale" used by Vaudour and Shaw (2005) for terroir zoning.

In this perspective, the aim of this paper is to prove that physically based approaches can be usefully employed also at very detailed scales such as for viticulture microzoning, in order to effectively separate different viticulture zones (functional homogeneous zones, fHZs) on the basis of their potential functionality (e.g. potential water stress) and by doing so better orient viticulture management.

This was done on an experimental site ( 2.3 ha over a homogeneous hilly slope) characterized by large soil variation under the very same climatic conditions.

\section{Materials and methods}

\subsection{Study area}

The study area is located in a hilly environment of southern Italy (Mirabella Eclano, AV, Campania region: lat $41.047808^{\circ}$, lon $14.991684^{\circ}$, elev. $368 \mathrm{~m}$ a.s.1.), in a farm oriented to the production of high-quality wines, namely Quintodecimo.

The study area is included in the "marlsandstone/carbonate hills" landscape system (D3). The only information on soil types is available on a rather coarse scale: a soil-landscape map of the whole Campania region at a 1:250000 scale (Di Gennaro et al., 2002).

The main soil types of the Mirabella Eclano area are identified as Haplic Calcisols and Calcaric Cambisols. However, considering the scale, this map cannot be employed to describe the soil type at the specific site of the experiment.
The vineyard studied was an Aglianico cultivar (controlled designation of origin - DOC/AOC), standard clone population planted in the year 2000 on 1103 Paulsen rootstocks (espalier system, cordon spur pruning, 5000 units per hectare) placed along a slope of length $90 \mathrm{~m}$ with an $11 \%$ gradient. Legume green manure management is applied.

The long-term (2003-2013) mean daily temperature annually of the study area was $14.7( \pm 0.9)^{\circ} \mathrm{C}$, while the mean annual rainfall was $802( \pm 129) \mathrm{mm}$ (data from the regional weather station of Mirabella Eclano, AV, at $1 \mathrm{~km}$ of study area)

Climate monitoring within the farm during the 2011 to 2013 vintage showed that during the cropping season (April to early October) the mean daily temperature was $20.9( \pm 1.2)^{\circ} \mathrm{C}$, while the precipitation was very variable during the three vintages, ranging from 285 to $200 \mathrm{~mm}$.

\subsection{Method used for mapping homogeneous zones}

The viticulture microzoning procedure used is rooted in procedures already applied at various scales. This includes standard soil mapping and geometric spatial analysis of solar radiation, bioclimatic indexes, morphometric data and remotely sensed images (Failla et al., 2004; Vaudour, 2001; Vaudour et al., 2010). Moreover, the procedure included geophysical mapping, which has proved to be also a very useful tool for soil spatial analysis in precision viticulture (Andrenelli et al., 2010; Priori et al., 2010, 2012).

More specifically, the employed procedure is given in the flow diagram in Fig. 1:

- Step 1: identification of homogeneous zones (HZs) obtained from standard soil mapping (landscape units, soil profiles, minipits, etc.) at a detailed scale supported by geophysical survey. These HZs were also statistically described in terms of their DTM- and DSM-derived parameters.

- Step 2: evaluation of the hydrological indicator of crop water status (potential crop water stress index - CWSI) by applying physically based simulation modelling to the representative soils of the previously defined HZs, and definition of functional homogeneous zones ( $\mathrm{fHZs}$ ).

- Step 3: vine/must/wine monitoring over the fHZs.

The realization of step 1 gives an advanced but "static" description of landscape useful for making a standard land evaluation (qualitative and empirical approach) to evaluate how suitable the land is for the vine. The innovation is enclosed in step 2, where a key component of the functional behaviour of soils to vine responses is described dynamically by means of a physically based approach (Bonfante et al., 2011). This last step makes it possible to discriminate soil behaviour through a hydrological indicator of plant water status (CWSI) and to identify the fHZs from the HZs. The term "functional" is 


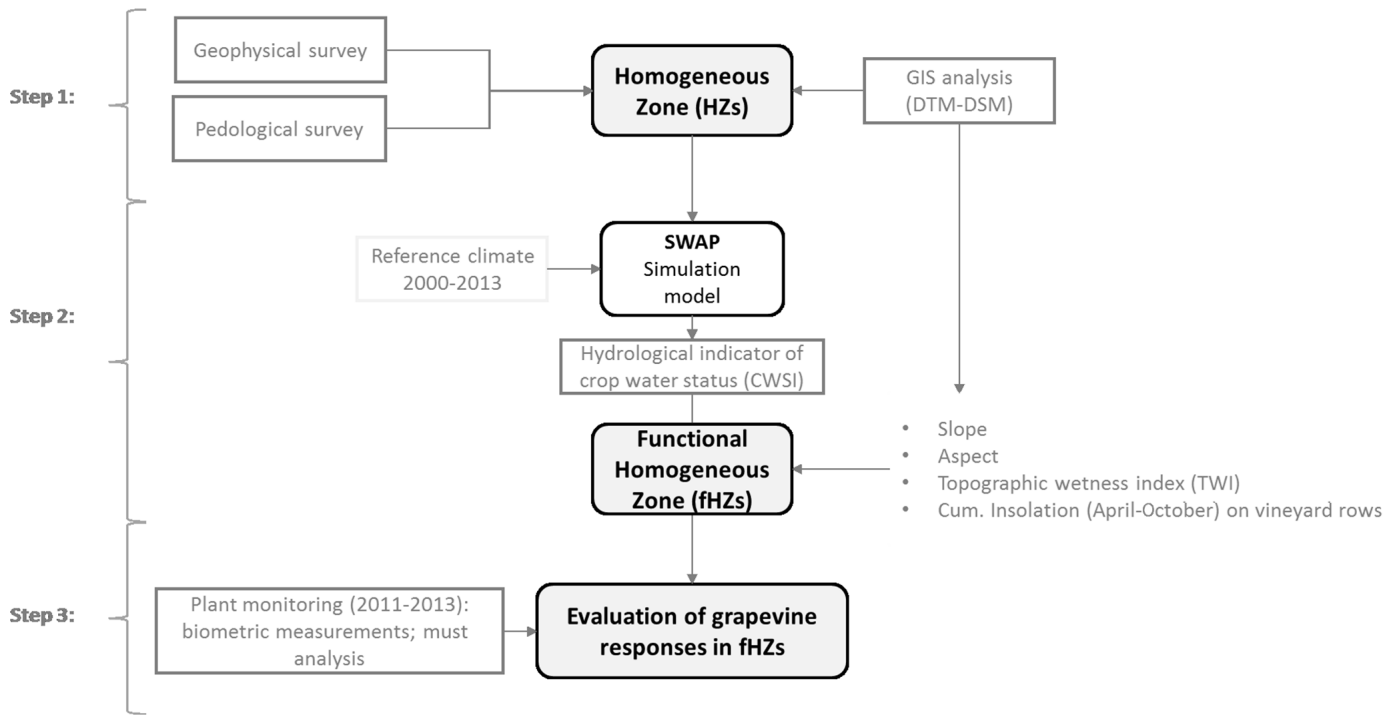

Figure 1. Flow diagram illustrating the proposed approach applied to the case study of the Quintodecimo farm.

employed in order to strengthen the soil-plant-climate functionality. Finally, step 3 allows evaluation of plant behaviour within any fHZs and testing of the occurring CWSI.

\subsection{Pedological survey and soil measurements}

A combined geophysical-pedological approach was used to derive the map of the HZs in the study area. These HZs were obtained after a detailed soil survey that was adapted to the specific need of this research. A preliminary map of the most important soil forming factors in the area was obtained by combining a geomorphological analysis of lidarderived DEM with local geological information. This led to the identification of the main soil-landscape units. The actual soil survey (soil profiles, minipit and augering) was supported by geophysical survey techniques. These techniques, based on non-invasive tools (generally applied to environmental studies, e.g. for geological prospecting), were used as very quick survey systems that gave initial information on the general spatial variability in the soils that were investigated, better planning of the field investigation in the pedological survey, and improvement in the soil map resolution, emphasizing the spatial soil micro-variability (traditional soil surveys and soil analysis are usually time-consuming and expensive, especially for high-resolution maps). Geoelectrical soil mapping has become widely accepted and considered as a successful geophysical method that provides the spatial distribution of relevant agronomic information for precision farming (Lück et al., 2009).

Methods based on electrical properties are particularly promising as support to pedological surveys because important soil physical properties are strongly correlated with electrical conductivity, which, changing in space, can represent spatial soil distribution. Geophysical methods offer a valu- able means for obtaining subsidiary data in an efficient way, and have been widely applied in soil sciences for a considerable period of time (Samouëlian et al., 2005).

In this study the apparent soil electric conductivity (ECa), was carried out by electromagnetic induction (EMI) sensors, which represents a very useful tool for identifying soil map units and soil properties in respect of clay content (Morari et al., 2009), soil depth (Saey et al., 2009), water content (Davies, 2004; Cousin et al., 2009; Lück et al., 2009; Tromp-van Meerveld and McDonnell, 2009) and water salinity (Doolittle et al., 2001).

However, soils, like every other geological material, are not uniform; consequently, what is specifically measured is an apparent ECa, which can be defined as the actual conductivity of a homogeneous and isotropic medium equivalent to a real heterogeneous and anisotropic medium.

The instrument used for surface mapping of the electric conductivity was the EM38-DD (Geonics Ltd., Ontario, Canada) used in both vertical dipole mode (VDM) and horizontal dipole mode (HDM). The sensor of instrument was calibrated to minimize the errors before the survey, which was performed in July 2011 during grape ripening. The instrument was placed on a PVC sledge and pulled by a tractor along the inter-rows, at a distance of about $5 \mathrm{~m}$ to avoid interference phenomena. The use of the sledge makes it possible to keep the instrument at a constant distance from the soil, making data acquisition easier and more accurate.

The data were recorded on a GPS-supplied data logger with European Geostationary Navigation Overlay Service (EGNOS) Wide Area Augmentation System (WAAS) correction (accuracy $\gg 3 \mathrm{~m}$ ), which made it possible to georeference and map the measured property. The instrument was set to acquire one measurement per second. 
Data post-processing was performed by means of ordinary kriging with $1 \mathrm{~m}$ resolution. The final result of the EM38-DD survey was therefore a regular grid of data points including ECa for two depths (1.6 $\mathrm{m}$ for VDM and $0.76 \mathrm{~m}$ for HDM). These horizontal (HDM) and vertical (VDM) ECa maps were used as baseline data for a pedological survey based on soil augerings and soil profiles descriptions. This was done similarly with the classical (overlying procedures) soil survey of other thematic layers (geology, geomorphology, etc.).

The soil profiles were described according to FAO (2006). Chemical analyses were performed according to the official methods of the Italian Ministry of Agriculture and Forestry (Colombo and Miano, 2015). The grain size distribution (GSD) was determined by a laser granulometer (Malvern Mastersizer 2000).

Undisturbed soil samples (volume $\cong 750 \mathrm{~cm}^{3}$ ) were collected from each soil horizon and hydraulic properties were determined in the laboratory to simulate the hydrological conditions of the soil by means of an agro-hydrological model, which is illustrated in Sect. 2.5.

Soil samples were saturated from the bottom and the saturated hydraulic conductivity was measured by means of a permeameter (Reynolds et al., 2002). After sealing the bottom surface to set a zero flux, measurements were then taken during drying: at appropriately pre-set time intervals, the weight of the whole sample and the pressure head at three different depths (by means of tensiometers) were determined. An iterative procedure was applied for estimating the water retention curve from these measurements. The instantaneous profile method was used to determine the unsaturated hydraulic conductivity. Moreover, some points at a lower water content of the dry branch of the water retention curve were determined by a dew-point system (WP4 dew-point potentiometer, Decagon Devices Inc.). Details on the tests and overall calculation procedures were described by Basile et al. (2012) and Bonfante et al. (2010).

\subsection{The hydrological indicator: CWSI}

The effects of water stress on wine quality, appearance, flavour, taste and aroma have been clearly highlighted by various authors (Matthews et al., 1990; Van Leeuwen et al., 2009; Chapman et al., 2005; Acevedo-Opazo et al., 2010; Intrigliolo and Castel, 2011; and Romero et al., 2013), differentiating also the effects between early or late water deficit treatments. The estimate of water stress at the different phenological stages can therefore represent an important tool in terroir classification. Different variables (e.g. air temperature, wet-bulb temperature) could be applied to develop a proper water stress index, but as reported by Kozak et al. (2006), the use of transpiration information is realistically more variable (in respect to evapotranspiration) for defining the crop water stress. In our approach, to simulate the soil water balance, we used a simulation model (SWAP) based on the Richards' equation. This model is very different from the one applied by Kozak et al. (2006). It is very robust for stimulating the soil water balance and, moreover, it has previously been used and tested in Italy and in the same region of Campania (Bonfante et al., 2010, 2011).

The stress index estimated from the model output is a daily CWSI, defined as follows:

$\mathrm{CWSI}=\left[1-\left(\frac{T_{r}}{T_{\mathrm{p}}}\right)\right] \times 100$,

where $T_{r}$ is the daily actual water uptake and $T_{\mathrm{p}}$ is the daily potential transpiration.

The sum of the daily CWSI in the required period represents the cumulated stress, $\mathrm{CWSI}_{\text {cum: }}$ :

$\mathrm{CWSI}_{\mathrm{cum}}=\frac{\left[\int_{t_{1}}^{t_{2}} 1-\left(\frac{T_{r}}{T_{\mathrm{p}}}\right) \times \mathrm{d} t\right]}{\left(t_{2}-t_{1}\right)} \times 100$.

The application of this index, changing the integration time $\left(t_{1}\right.$ and $\left.t_{2}\right)$, makes it possible to estimate plant water stress at different stages of crop growth (shoot growth, flowering, berry formation, berry ripening) (Fig. 2).

Finally, this index was used to analyse the HZs behaviours and successively to define the fHZs.

\subsection{Simulation modelling}

The Soil-Water-Atmosphere-Plant (SWAP) model (Kroes et al., 2008) was applied to solve the soil water balance and to calculate the CWSI for each soil identified by the soil survey. It has already been used in viticulture by various authors (Ben-Asher et al., 2006; Minacapilli et al., 2009; Bonfante et al., 2011; Rallo et al., 2012).

SWAP is an integrated physically based simulation model of water, solute and heat transport in the saturatedunsaturated zone in relation to crop growth. In this study only the water flow model was used; it assumes a 1-D vertical flow processes and calculates the soil water flow using the Richards equation:

$C(h) \times \frac{\partial h}{\partial t}=\frac{\partial\left[K(h) \times\left(\frac{\partial h}{\partial z}+1\right)\right]}{\partial z}-S(h)$,

where $C(h) \times \frac{\partial \theta}{\partial h}$ is the differential soil water capacity, $\theta$ $\left(\mathrm{cm}^{3} \mathrm{~cm}^{-3}\right)$ is the volumetric soil water content, $h(\mathrm{~cm})$ is the soil water pressure head, $t(\mathrm{~d})$ is the time, $z(\mathrm{~cm})$ is the vertical coordinate taken positively upward, $K\left(\mathrm{~cm} \mathrm{~d}^{-1}\right)$ is the hydraulic conductivity and $S\left(\mathrm{~cm}^{3} \mathrm{~cm}^{-3} \mathrm{~d}^{-1}\right)$ is the water extraction rate by plant roots.

Soil water retention is described by the unimodal $\theta(h)$ relationship proposed by van Genuchten (1980), expressed in terms of the effective saturation, $S_{\mathrm{e}}$, as follows:

$S_{\mathrm{e}}=\left[\frac{1}{1+(\alpha|h|)^{n}}\right]^{m}$, 


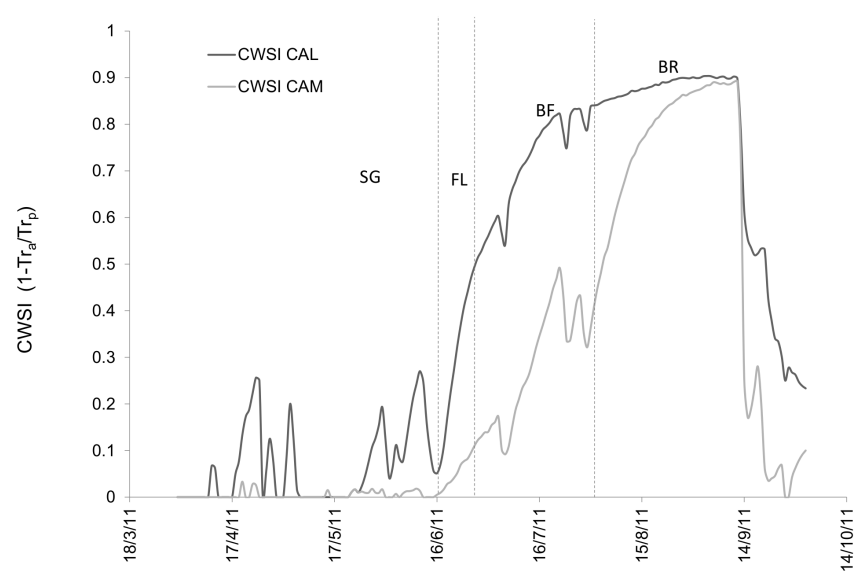

Figure 2. The crop water stress index (CWSI) simulated by SWAP in the HZs CAL and CAM in the year 2011 during the cropping season. (SG: shoot growth; FL: flowering; BF: berry formation; BR: berry ripening).

where $S_{\mathrm{e}}=\frac{\left(\theta-\theta_{\mathrm{r}}\right)}{\left(\theta_{0}-\theta_{\mathrm{r}}\right)} ; \theta_{\mathrm{r}}$ and $\theta_{0}$ are the residual water content and the water content at $h=0$, respectively; and $\alpha\left(\mathrm{cm}^{-1}\right), n$ and $m$ are curve-fitting parameters.

Mualem's expression (Mualem, 1976) is applied to calculate relative hydraulic conductivity, $K_{\mathrm{r}}$. Assuming $m=\frac{1-1}{n}$, van Genuchten (1980) obtained a closed-form analytical solution to predict $K_{\mathrm{r}}$ at a specified volumetric water content:

$K_{\mathrm{r}}\left(S_{\mathrm{e}}\right)=\frac{K\left(S_{\mathrm{e}}\right)}{K_{0}}=S_{\mathrm{e}}^{\tau} \times\left[1-\left(1-S_{\mathrm{e}}^{\frac{1}{m}}\right)^{m}\right]^{2}$,

where $K_{0}$ is the hydraulic conductivity measured at $\theta_{0}$ and $\tau$ is a parameter which accounts for the dependence of the tortuosity and partial correlation between adjacent pores.

The condition at the bottom boundary can be set in several ways (e.g. pressure head, water table height, fluxes, impermeable layer, unit gradient).

The upper boundary conditions of SWAP in agricultural crops are generally described by the potential evapotranspiration $\mathrm{ET}_{0}$, irrigation and daily precipitation. The potential evapotranspiration is then partitioned into potential evaporation, $E_{\mathrm{p}}$, and potential transpiration, $T_{\mathrm{p}}$, according to the LAI evolution, following the approach of Ritchie (1972).

SWAP simulates water uptake and actual transpiration according to the model proposed by Feddes et al. (1978), where the root water uptake, $S$, is described as a function of the pressure head, $h$ :

$S(h)=\alpha(h) \times S_{\max }=\alpha(h) \times \frac{T_{\mathrm{p}}}{\left|z_{\mathrm{r}}\right|}$,

where $z_{\mathrm{r}}(\mathrm{cm})$ is the thickness of the root zone and $\alpha(h)$ is a semi-empirical function of the pressure head $h$, varying between 0 and 1 . The shape of the function $\alpha(h)$ depends on four critical values of $h$, which are related to crop type and potential transpiration rates. The actual transpiration rate $T_{\mathrm{a}}$ $\left(\mathrm{cm} \mathrm{d}^{-1}\right)$ is computed by the integration of $S$ over the root layer. The root depth is specified by the user as a function of the development stage.

Model parameters and data for simulations are as follows:

- The upper boundary condition comes from the daily data of the Mirabella Eclano regional weather station ( $1 \mathrm{~km}$ from the study area) integrated with the micrometeorological station located at the farm. Daily potential evapotranspiration $\left(\mathrm{ET}_{0}\right)$ was determined by applying the Penman-Monteith equation.

- The bottom boundary condition was set as a unit gradient.

- Crop data. The leaf area index was measured in different phenological phases by a ceptometer, rooting depth was measured during the profile description, and the water uptake function parameters were derived from literature (Taylor and Ashcroft, 1972).

- The hydraulic properties were parameterized by fitting a procedure of the van Genuchten-Mualem model to the experimental data (see Sect. 2.2).

The SWAP model was previously calibrated and validated in both representative soils from the study area, on the soil water content measured at different soil depths by TDR probes (five soil depths until $100 \mathrm{~cm}$ ) in the years 2011 and 2012, respectively. In particular, the root-mean-square error (RMSE) (Loague and Green, 1991) showed values (over all of the soil profile depth) of $0.034( \pm 0.03)$ for the Calcisol and $0.032( \pm 0.01)$ for the Cambisol, with a correlation index " $r$ " of $0.75( \pm 0.3)$ and $0.90( \pm 0.1)$, respectively. Indexes are a weighted average over depths along the profile, until $-100 \mathrm{~cm}$, rooting zone.

The RMSE values agree with those shown in a previous study (Bonfante et al., 2010). Moreover, Sheikh and van Loon (2007) reported several RMSE values obtained from calibration and validation procedures by Heathman et al. (2003), Crescimano and Garofalo (2005), Mertens et al. (2005), Singh (2005), Wegehenkel (2005) and Sheikh and van Loon (2007). Most of these results have a range of 0.030.05. Finally, Eitzinger et al. (2004), comparing the SWAP, CERES and WOFOST models, obtained RMSE values ranging from 0.007 to 0.07 for different soils, models and crops.

We can therefore consider the application of SWAP in both soils as being good for predicting the soil water balance.

\subsection{GIS analysis: DTM and DSM information}

A high-resolution digital surface model (DSM) and a digital terrain model (DTM) of the study area were acquired (DTM in April 2011, $1 \mathrm{~m}$ spatial resolution, and DSM in July 2013, $0.30 \mathrm{~m}$ spatial resolution) with lidar technologies, as part of an ongoing project in the study area. These models represent the elevation values of the ground level plus those 
above ground (i.e. canopy). They were processed using specific software coupled with the GIS environment (ArcGIS, QGIS and SAGA open source software) to support the procedures of step 1 concerning (i) the geomorphological analysis for the pedological survey (identification of preliminary landscape mapping units), and (ii) to investigate the variation of the study area within the HZs. These high-spatial-resolution acquisitions gave detailed auxiliary spatial information such as the estimate of solar radiation taking into consideration shadows from vineyards. Specifically, continuous maps of slope, aspect and topographic wetness index (TWI) were obtained from the DTM and potential insolation at very high spatial resolution from the DSM. More specifically, these last derived maps were realized considering the presence of vineyard rows as a 3-D objects in space, able to influence insolation through the formation of intra-row shadows. Subsequently, all of this information was used to characterize the differences between the fHZs identified in the vineyard.

\subsection{Crop measurements}

Monitoring was conducted for 3 years (2011 to 2013) within the fHZs (identified in step 2) on the vegetative growth of 27 plants (54 plants over 2.3 ha) until the harvest. The measurements were realized randomly on a weekly or biweekly basis, in relation to the measured variable and the physiological crop stage.

The midday leaf water potential (LWP; MPa) was assessed for each fHZs on a set of 10 plants randomly chosen between the 27 plants monitored, using a Scholandertype pressure bomb (SAPS II, 3115, Soilmoisture Equipment Corp., Santa Barbara, CA, USA). Photosynthetic $\mathrm{CO}_{2}$ assimilation $\left(\mu \mathrm{mol} \mathrm{m} \mathrm{m}^{-2} \mathrm{~s}^{-1}\right)$, stomatal conductance to water vapour $\left(\mathrm{mol} \mathrm{m}^{-2} \mathrm{~s}^{-1}\right)$ and effective quantum yield of PSII photochemistry (ФPSII) in light-adapted leaves were measured by means of a portable photosynthesis system ( $\mathrm{Li}$ 6400-40, LI-COR, Lincoln, NE, USA). The light source was set at a saturating photosynthetic photon flux density of $1800 \mu \mathrm{mol} \mathrm{m} \mathrm{m}^{-2} \mathrm{~s}^{-1}$, while the external $\mathrm{CO}_{2}$ source was set at $370 \mu \mathrm{mol} \mathrm{mol}^{-1}$. The instrument software calculated the various gas-exchange parameters on the basis of the von Caemmerer and Farquhar (1981) model, and ФPSII according to Genty et al. (1989). The chlorophyll content of the leaves was optically estimated as a relative index (CCL) using a handheld meter (CCM200, chlorophyll content meter, Apogee Instruments Inc., Logan, UT, USA) as the ratio of the fractional transmittances at 653 and $931 \mathrm{~nm}$.

A linear Accupar LP-80 PAR-LAI ceptometer (Decagon Devices Inc., Pullman, WA, USA) was used to measure light interception by the vineyard and to estimate the LAI. The ceptometer had 80 photosynthetic photon flux density (PPFD) sensors spaced at $1 \mathrm{~cm}$ intervals, and it was programmed to average readings of 10 sensors at a time before logging data. The PPFD transmitted through the canopy (PPFDt) was measured at $0.25 \mathrm{~cm}$ above soil surface over a grid of $0.1 \mathrm{~cm} \times 0.1 \mathrm{~cm}$ across an area of length $2 \mathrm{~m}$ and with $2 \mathrm{~m}$ between the rows. The measurements were carried out in 3-4 replicates in both CAL and CAM sites, while the measurements taken in a clear area near the two sites were taken as the PPFD incident over the canopy (PPFDl). Intercepted light (PPFDint) was calculated as the difference between incident and transmitted PPFD, whereas the fractional light interception (fi) was calculated as the ratio between PPFDint and PPFDl. Statistically significant differences between the means of the analysed variables for the two sites were evaluated using the Student $t$ test. A null hypothesis was rejected at $P \leq 0.05$.

\subsection{Must/wine characteristics}

In addition to the crop measurements, the must and wine characteristics were monitored within the fHZs (identified in step 2) on 27 plants for 3 years (2011 to 2013). In particular, of the 27 plants monitored, 12 were used for grape collections at harvest and 15 for sampling of scalar grapes (randomly sampled at each measurement date).

The standard chemical analyses and spectrophotometric measurements of must and wine were carried out as follows.

Standard chemical analyses (soluble solids, total acidity, $\mathrm{pH}$, and total polyphenols (Folin-Ciocalteau index)) and absorbances (Abs) were measured according to the OIV Compendium of International Methods of Analysis of Wine and Musts (OIV, 2007). Colour intensity (CI) and hue were evaluated according to the Glories (1984) method. Total anthocyanins were determined by the spectrophotometric method based on $\mathrm{SO}_{2}$ bleaching (Ribéreau-Gayon and Stonestreet, 1965). Tannins were determined according to RibèreauGayon and Stonestreet (1966). Analyses were performed in duplicate using basic analytical equipment and a Shimadzu UV-1800 (Kyoto, Japan) UV spectrophotometer.

Polyphenol was extracted from the grapes as follows. The separate extraction of berry components was carried out in duplicate, simulating the maceration process necessary for the production of red wines (Mattivi et al., 2002; Vacca et al., 2009). Briefly, berries (200 g) were cut in two with a razor blade, and seeds and skins were carefully removed from each half of the berry. The pulp on the inner face of the berry skin was removed using an end-flattened spatula in an attempt to preserve skin integrity. Skins and seeds were immediately immersed in a $200 \mathrm{~mL}$ solution of ethanol: water $(12: 88 \mathrm{v} / \mathrm{v}), 100 \mathrm{mg} \mathrm{L}^{-1}$ of $\mathrm{SO}_{2}, 5 \mathrm{~g} \mathrm{~L}^{-1}$ of tartaric acid and a pH value adjusted to 3.2 (with $\mathrm{NaOH}$ ) and extracted for 5 days at $30^{\circ} \mathrm{C}$. The extracts were shaken by hand once a day. Skins and seeds were removed from the hydro-alcoholic solution after 5 days and the skin extract was centrifuged for $10 \mathrm{~min}$ at $3500 \mathrm{~g}$. Extracts were poured into dark glass bottles, flushed with nitrogen and stored at $4{ }^{\circ} \mathrm{C}$ until spectrophotometric analyses. 
Quantitative data relative to the phenolic compounds of the treated wines were compared using Fisher's least significant difference (LSD) procedure. Analyses were performed using XLSTAT (Addinsoft, XLSTAT version 2013.6.04). All data are means of four values ( 2 experimental replicates $\times 2$ analytical replicates).

\section{Results and discussion}

\section{1 $\mathrm{HZ}$ identification after soil and geophysical mapping}

In order to identify potentially different environments leading to HZs, we performed a standard soil mapping procedure adapted to the specific needs of this research. The combination of a geomorphological analysis of lidar-derived DEM and local geological data led to the production of preliminary landscape mapping units. These mapping units (not reported) depict three different environments, namely (i) a summit landscape unit with a slope gradient of about 5$10 \%$ developed over clayey sediments with clear signs of local erosional processes, (ii) an upslope landscape unit with a slope gradient of about $25-30 \%$ developed over clayey sediments with few signs of erosional processes, and (iii) a downslope landscape unit with a slope gradient of about $7-$ $15 \%$ developed over a colluvium landform with no signs of erosion.

An EMI survey was then conducted on these units to orient the pedological survey (also in terms of soil variability) and to define the boundaries of HZs.

The ECa maps obtained were used as baseline data in the pedological survey.

The ECa maps (Fig. 3) showed that the vineyard was clearly characterized by the presence of two major patterns of ECa, generally homogeneous, corresponding to two areas: (i) summit and upper slope (red area in Fig. 3d) and (ii) down-slope (bluish area in Fig. 3d). The ECa mean difference between the two areas was statistically significant $(P<0.05)$. The difference between summit and upslope previously observed by the preliminary landscape analysis (on high-resolution DTM), however, did not always correspond to the ECa mapping and, moreover, the boundaries between the two main areas identified by the ECa pattern is oblique (with respect to slope) and not linear, as would be expected with DTM analysis.

Landscape mapping unit analysis was combined with ECa mapping, observing ECa homogeneous and heterogeneous areas, and performing 25 qualitative rapid soil observation (minipits, augers). Six soil profiles and 10 augers were localized to include major variability (Fig. 3a). The soil profiles and augers were described and sampled. Bulk and undisturbed soil samples were collected from each described soil horizon and submitted for chemical and physical analysis.

From the pedological characterization (76 soil samples in total, 51 from 6 soil profiles and 25 from augers; auger data are not shown), two main soil types were identified: Cambic
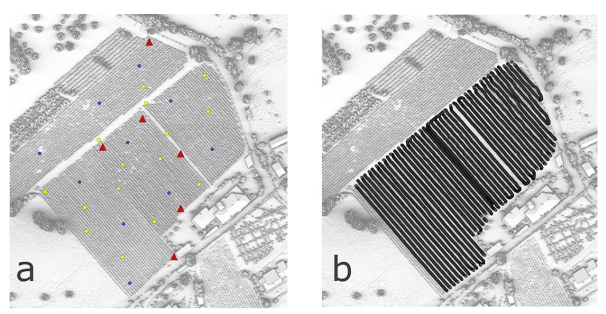

$\triangle$ Soil Profile

Rapid Soil observation

- Soil Augers
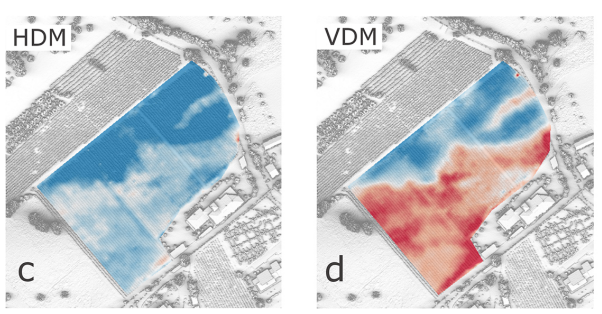

$\mathrm{ECa}(\mathrm{ms} / \mathrm{m})$

$\square<37$

37-53

53-69

69-85

85- $>101$

Figure 3. (a) Location of soil profiles, augers and rapid observation (minipits, augers), (b) local acquisition recorded by GPS, (c) ECa map of horizontal dipole mode (HDM), and (d) ECa map of vertical dipole mode (VDM).

Calcisol (Clayic, Aric) and Eutric Cambisol (Clayic, Aric, Colluvic) (FAO, 2014).

These soils are likely to have evolved from a different parent material; the Cambisol evolved over colluvium (including traces of pumices), not present in the upper part of the vineyard, while the Calcisol evolved from the clayey sedimentary bedrock. The different origin is also expressed by the soils colour: brown (10YR) for the Cambisol and yellowish (5Y) for the Calcisol.

Calcisol is richer in total carbonates than Cambisol (mean 232.7 and $41.2 \mathrm{~g} \mathrm{~kg}^{-1}$, respectively), with a Bk horizon at a depth of about $45 \mathrm{~cm}$, with the common accumulation of carbonates. This induces a differentiation of the $\mathrm{pH}$ between the two pedons (Calcisol mean 8.2; Cambisol mean 7.0). The organic carbon content (OC) and cation exchange capacity (CEC) were higher in the Cambisol (average values of OC in the topsoil were 1.0 and $2.1 \%$ for the Calcisol and Cambisol, respectively; average value of CEC along the soil profile was $24.3 \mathrm{cmol} \mathrm{kg}^{-1}$ in the Cambisol and $16.8 \mathrm{cmol} \mathrm{kg}^{-1}$ in the Calcisol). The apparent ECa is generally low in both soils, highlighting the absence of significant quantities of salts in solution (173 and $246 \mathrm{mS} \mathrm{cm}^{-1}$ for the Cambisol and Calcisol, respectively). The texture is clay loam in both soils.

The physical characteristics of two soil profiles, representative of the two soil types indicated, are reported in Table 1.

Despite the similar texture, the hydraulic properties measured in the lab showed some important differences (Table 1).

Among them, (i) Calcisol showed a pronounced vertical heterogeneity (i.e. the $K_{0}$ and 1 of the Bk horizon are very different from the adjacent upper and lower horizons); (ii) Cambisol showed a relative vertical homogeneity, especially in the Bw horizons; and (iii) despite the fact that the porosity of Calcisol is higher than that of Cambisol (see saturated soil 
Table 1. Physical properties of Calcisol (CAL HZ) and Cambisol (CAM HZ).

\begin{tabular}{|c|c|c|c|c|c|c|c|c|c|c|c|}
\hline \multirow[t]{3}{*}{ Soil/HZ } & \multirow{2}{*}{\multicolumn{2}{|c|}{$\begin{array}{l}\text { Soil horizon and } \\
\text { thickness }(\mathrm{cm})\end{array}$}} & \multicolumn{3}{|c|}{ Particle size fraction } & \multirow{3}{*}{$\begin{array}{r}\text { Rock } \\
\text { fragments }\end{array}$} & \multicolumn{5}{|c|}{ Hydrological properties } \\
\hline & & & Clay & Silty & Sand & & \multirow{2}{*}{$\frac{\Theta_{0}}{\left(\mathrm{~m}^{3} \mathrm{~m}^{-3}\right)}$} & \multirow{2}{*}{$\begin{array}{r}K_{0} \\
\left(\mathrm{~cm} \mathrm{~d}^{-1}\right)\end{array}$} & \multirow{2}{*}{$\frac{\alpha}{\left(1 \mathrm{~cm}^{-1}\right)}$} & \multirow[t]{2}{*}{$l$} & \multirow[t]{2}{*}{$n$} \\
\hline & & & & $100 \mathrm{~g}^{-}$ & & & & & & & \\
\hline \multirow{5}{*}{$\begin{array}{l}\text { Cambic Calcisol } \\
\text { (Clayic, Aric)/ } \\
\text { CAL }\end{array}$} & Ap1 & $0-10 / 20$ & 31.9 & 38.1 & 30.1 & $\mathrm{a}$ & 0.575 & 669.3 & 0.642 & -1.78 & 1.30 \\
\hline & Ap2 & $10 / 20-45$ & 32.0 & 37.7 & 30.3 & $\mathrm{a}$ & 0.474 & 171.5 & 0.223 & -3.44 & 1.10 \\
\hline & $\mathrm{Bk}$ & $45-80$ & 32.6 & 39.7 & 27.7 & $\mathrm{a}$ & 0.435 & 9.7 & 0.126 & -12.81 & 1.10 \\
\hline & $\mathrm{BC}$ & $80-105$ & 33.8 & 39.3 & 27.0 & $\mathrm{a}$ & 0.390 & 995.0 & 0.074 & 1.46 & 1.23 \\
\hline & $\mathrm{CB}$ & $105-130+$ & 34.9 & 37.6 & 27.5 & $\mathrm{a}$ & 0.543 & 1000.0 & 0.078 & 0.50 & 1.23 \\
\hline \multirow{4}{*}{$\begin{array}{l}\text { Eutric Cambisol } \\
\text { (Clayic, Aric, } \\
\text { Colluvic)/CAM }\end{array}$} & Ap & $0-40$ & 34.2 & 31.5 & 34.4 & $\mathrm{a}$ & 0.484 & 179.1 & 0.008 & -1.00 & 1.45 \\
\hline & Bw1 & $40-90$ & 37.6 & 30.0 & 32.5 & $\mathrm{~b}$ & 0.462 & 2.3 & 0.003 & -1.00 & 1.21 \\
\hline & Bw2 & $90-120$ & 42.9 & 29.5 & 27.7 & b & 0.387 & 3.7 & 0.005 & -1.00 & 1.15 \\
\hline & Bw3 & $120-160+$ & 41.1 & 30.8 & 28.1 & b & 0.416 & 19.0 & 0.021 & -2.70 & 1.17 \\
\hline
\end{tabular}

a: absent; b: few fine sub-rounded pumiceous stones.
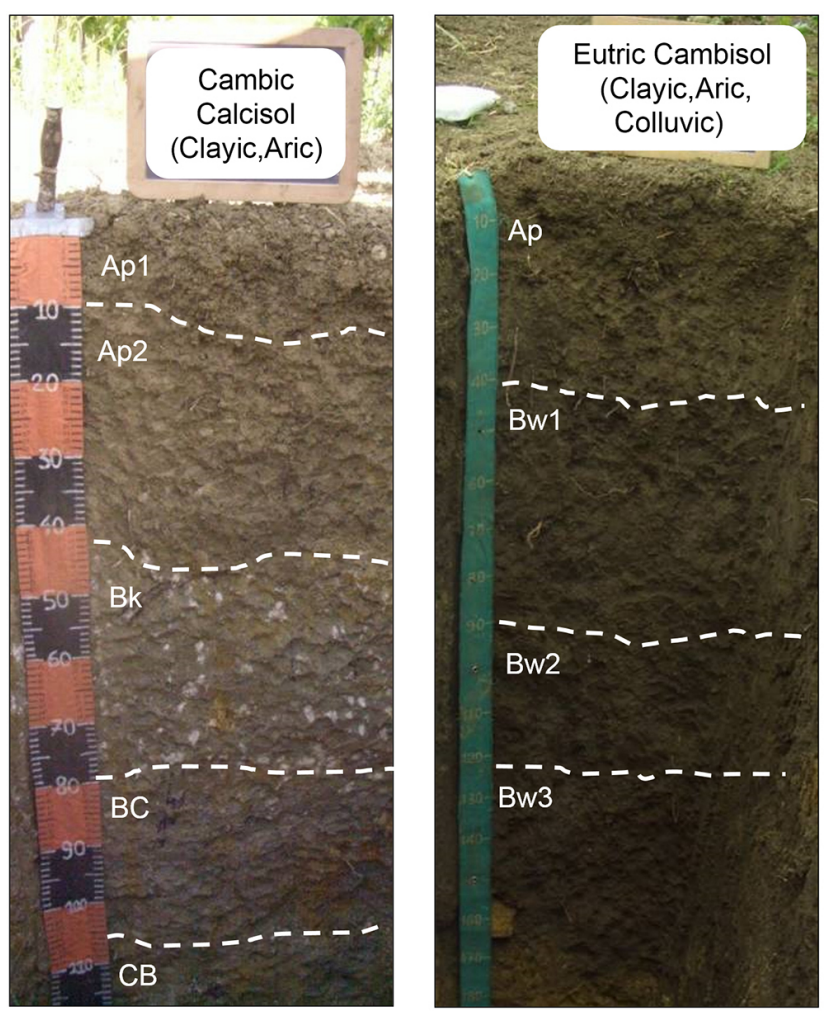

Figure 4. The representative soils of CAL and CAM HZs: Cambic Calcisol and Eutric Cambisol, respectively.

water contents, $\theta_{0}$ ), the available water content (AWC) in the first $80 \mathrm{~cm}$ of soil depth was lower (i.e. Calcisol $80 \mathrm{~mm}$ and Cambisol $145 \mathrm{~mm}$ ).

Integrating the soil and geophysical survey with the physical, hydrological and chemical soil analysis made it possible to separate two main HZs:

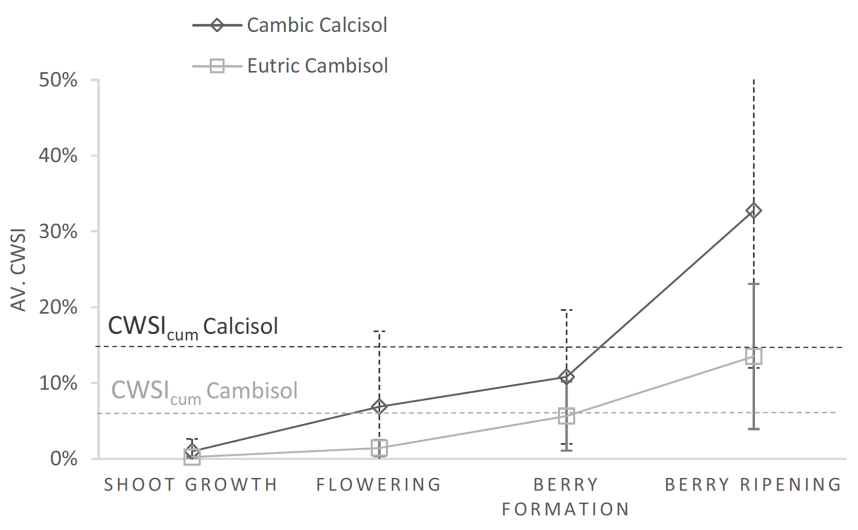

Figure 5. The average values and standard deviation of the potential CWSI during the cropping season (reported in terms of phenological phases) of vines cultivated in the representative soils of homogeneous zones (CAL and CAM). The simulations were performed with SWAP models during the vintages from 2003 to 2013.

- CAL: Cambic Calcisol (Clayic, Aric) (Fig. 4) developing at the summit and in the upslope landscape position.

- CAM: Eutric Cambisol (Clayic, Aric, Colluvic) (Fig. 4) developing in the downslope landscape position.

\subsection{Modelling application (potential CWSI estimation)}

The potential CWSI data were obtained by analysing the water balance in the soil-vegetation-atmosphere (SVA) system in the two HZs using the SWAP hydrological model applied over 11 years of daily climate data (2003-2013). This information is especially important because it helps in evaluating the dynamics of the water stress of the soils present in the study area, representing a very powerful tool for vineyard planning. 
Table 2. Summary of results obtained in CAL and CAM HZs and CAL and CAM fHZs: (i) GIS analysis on DSM and DTM, (ii) simulation modelling application, and (iii) plant monitoring and the characteristics of bunches during the 3 years of monitoring (2011 to 2013) on Aglianico cultivar.

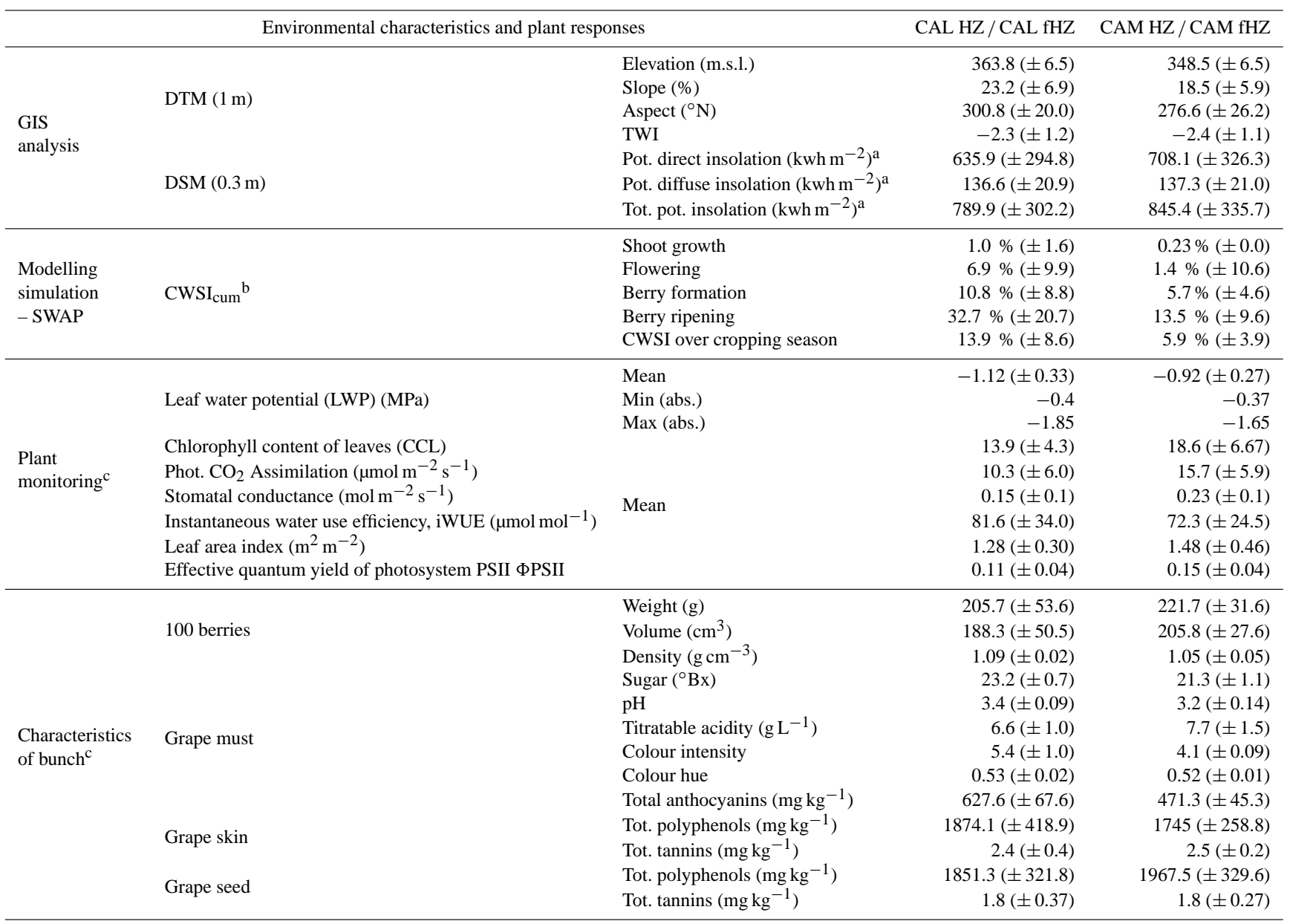

a The potential insolation refers to the period 1 April to 15 October. ${ }^{\text {b }}$ Average values calculated over 11 years (2003-2013). ${ }^{\mathrm{c}}$ Average over three seasons of measurements (2011 to 2013).

In particular, the level of CWSI between the two HZs in each plant phenological phase (Figs. 2 and 5) can be compared, defining the fHZs on the basis of their similarity in functional behaviour in relation to vines and correlate it with different plant responses in terms of must quality and plant production.

On average, in CAL the potential CWSI was 2 times higher (13.9\%) than CAM (5.9\%), with clearly different increases during the cropping season (from flowering to harvesting) (Table 2, Figs. 2 and 5).

The maximum values of CWSI were obtained during berry formation, with average values of $32.7 \%( \pm 20.7)$ for CAL and $13.5 \%( \pm 9.6)$ for CAM.

From the results of potential CWSI analysis, it is clear that the two representative soils of the study area, under the same climate and plant conditions, show a different susceptibility to vineyard water stress. These results mean that the two identified CAL and CAM HZs behave as HZs also in terms of their functional behaviour. To describe this output of the microzoning procedure from here onwards we shall refer to CAL and CAM functional homogeneous zones as CAL and CAM fHZs.

The statistical ANOVA on CWSI cum $_{\text {over the seasons }}$ showed a significant difference, with an alpha of 0.02 between the two soils. During the different phenological phases only the berry ripening phase showed a significant differences with an alpha of 0.02 . This behaviour can be explained considering that both soils started the growing season with an optimum water content (accumulated during the winter), but during the season, the reduction in rainfall, the increase in $\mathrm{ET}_{0}$ and the effect of plant water uptake emphasize the physical differences of these two SPA systems. Concerning the high variability in SD during berry ripening, the differences depend on different climate conditions, in particular rainfall amount, during the 11 years analysed. We can clearly identify two very dry years (2003 and 2007) and two very wet years (2005 and 2010). 
During the simulated years, the average rainfall in the period from 18 August to 15 October was $105 \mathrm{~mm}$, with a SD of 46.9 (44\% variation).

\subsection{GIS analysis}

Each functional $\mathrm{HZ}$ was then analysed with respect to the variability in environmental characteristics derived from the high-resolution DMS and DTM (Table 2, Fig. 6). The elevation and slope of CAL was higher compared to those of CAM; their mean difference is always significant $(P<0.05)$ and was about $15 \mathrm{~m}$ for the elevation and $4.7 \%$ for the slope gradient. These differences are consistent with both geomorphic and soil settings.

The aspect shows a northwest and west orientation for CAL and CAM fHZs, respectively. This aspect difference $(P<0.05)$ induces - in the vineyard rows - a differentiation in terms of total potential insolation $(P<0.05)$ during the cropping season (1 April to 15 October), which is about $55 \mathrm{kwh} \mathrm{m}^{-2}$ higher in the case of the CAM fHZ. Such differences are mainly due to the direct vineyard row insolation. This different insolation was tested directly on the Penman-Monteith equation; results showed a negligible effect on evapotranspiration and then on CWSI, as predicted by the model. A direct effect on grape bunches in terms of temperature could likely be realizable, but this aspect was not treated in this work.

\subsection{Vineyard records (crop/must measurements)}

The experimental plots were identified inside the two fHZs, and the phenological and physiological vine data were collected on 27 plants (randomly sampled at each measurement date) over 3 years (2011-2013).

Even though the experimental plots had the same cultivar (Aglianico), rootstocks (1103P) and management, the crop responses in terms of biomass development and must quality were very different.

Plants of CAM showed more vigour when compared to those of CAL (at fruit thinning, an average value of 11.1 bunches per plant vs. 10.0 was measured, with a peak of 14.6 vs. 8.7 bunches per plant in the year 2011). Despite a very similar number of bunches per plant at harvesting (average value of 4.6 bunches per plant for CAM and CAL, respectively), at harvest time the plant production of CAM was generally higher $\left(1.81 \pm 0.29 \mathrm{~kg} \mathrm{plant}^{-1}\right)$ compared to that of CAL $\left(0.97 \pm 0.36 \mathrm{~kg} \mathrm{plant}^{-1}\right)$. The last results regarding the different berry weight and volume recognized during the 3 years (Table 2) are in agreement.

The analyses carried out on grape bunches over the 3 years of measurement showed a very robust qualitative differentiation between the two fHZs. Investigated parameters like sugar, anthocyanins, polyphenols in the skin, colour intensity, tannins in the skin and $\mathrm{pH}$ were always higher in CAL during berry ripening compared to CAM. However, the
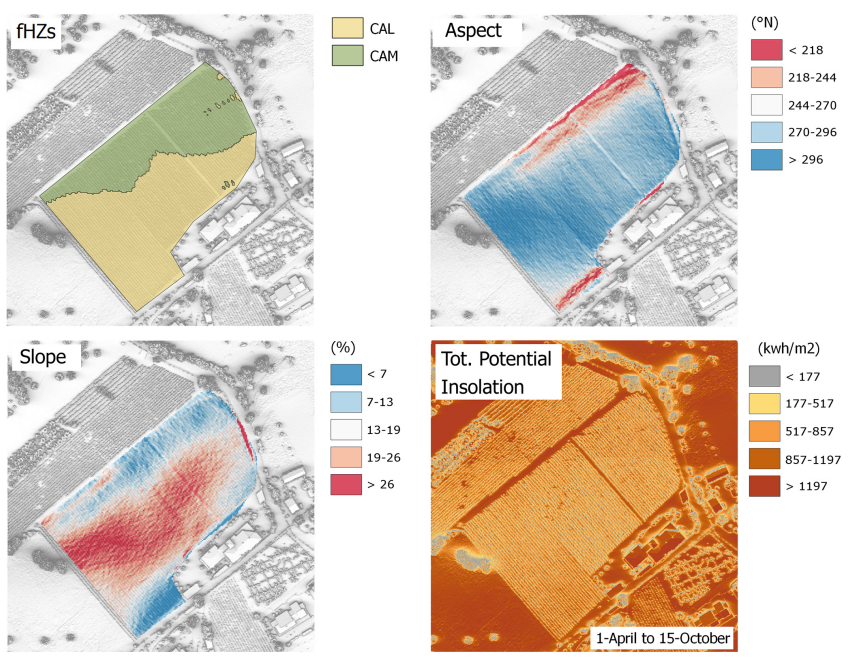

Figure 6. The functional homogeneous zones (fHZs) identified in the study area and the three maps derived from DSM and DTM analysis in a GIS environment: aspect, slope and total potential insolation.

titratable acidity, bunch volume and weight of 100 berries were lower in the CAL. The first results of microvinification showed higher values of ethanol $(12.2 \%$ vol for CAM and $13.3 \%$ vol for CAL), colour intensity ( 7.8 for CAM and 12.8 for CAL) and tannins $\left(2.9 \mathrm{~g} \mathrm{~L}^{-1}\right.$ for CAM and $4.6 \mathrm{~g} \mathrm{~L}^{-1}$ for CAL) in CAL than in CAM.

ANOVA analysis showed that during the 3 years only the total anthocyanins and colour intensity of the grape must were significantly affected by soil characteristics $(P>0.05)$. These results are in agreement with previous findings showing that moderate, and not severe, water stress or drought stress increases anthocyanins concentrations in berry skins (Ojeda et al., 2002). Among the 3 years considered, 2013 stands out because the grapes showed a lower content of sugars, a higher weight and a lower density of berries, mainly due to the fact that during 2013 the temperatures were lower and the ripening season was rainy. As a consequence, degreeday accumulation was slower and the berries larger due to their watering.

In both fHZs the minimum absolute values of $\operatorname{LWP}(-0.37$ and $-0.40 \mathrm{MPa}$ in CAM and in CAL, respectively) were registered at the beginning of crop season, while the maximum absolute values were reached at the end of August $(-1.65$ and $-1.85 \mathrm{MPa}$ in CAM and in CAL, respectively). Nevertheless, during the 3 years of measurements the plants on Calcisol (CAL fHZ, upslope) faced a more intense water stress than those in Cambisol (CAM fHZ, downslope) during the whole season. Consequently, stomatal conductance values during the 3 years agreed with those of LWP, with the Calcisol plants experiencing lower values and thus lower transpiration rates than those of Cambisol. Assimilation rates followed the same behaviour of stomatal conductance, highlighting that the plants in CAM had a more pro- 
nounced photosynthetic activity than those of CAL; in agreement with that, the quantum yield of photosystem PSII in leaves adapted to light (PHIPSII) also showed that CAM plants were more efficient than CAL plants in capturing the energy of the light absorbed by the photosystem PSII. Both photosynthetic activity and PHI PSII responded proportionally to the different chlorophyll a content, with the CAM plants showing the highest values. The LAI was lower in CAL plants (average 1.28) than in CAM plants (average 1.48), as a consequence of the more severe water stress suffered by plants grown in the former. Moreover, during the 3 years of the experiment (2011-2013), the differences between the two fHZs of all parameters monitored on the plant were significant, with $P<0.001$ ( $t$ test, two-tailed). Only the LAI showed a $P$ value of 0.014 .

\section{Discussion}

The effects of soil combination and climate on vine responses in terms of must characteristics and wine quality are well reported in the literature as the basis of the terroir concept. With this work, conducted in a small study area, the usefulness of the adopted microzoning procedure was tested by quantifying the effect of soil properties on plant responses and must characteristics.

The effectiveness of the results achieved lies in the specific experimental setup that was conducted in the same geomorphic land system, under the same climate conditions (only $90 \mathrm{~m}$ of slope, with about $15 \mathrm{~m}$ difference in elevation) on the same plant cultivar (Aglianico monoclonal population) and under the same vine management.

We believe that, under these conditions, the large-scale soil survey supported by the EMI survey represented a very good cost/benefit approach to investigating vineyard potentialities in view of a soil-plant-climate relationship study. Indeed, the EMI approach made it possible to immediately identify a homogeneous pattern on which to focus the sampling activities.

The identification and mapping at vineyard scale of the main soil types included in the fHZs - CAL fHZ, Cambic Calcisol (Clayic, Aric), and CAM fHZ, Eutric Cambisol (Clayic, Aric, Colluvic) - allowed us to estimate and study the different behaviour, in terms of crop water stress, of these two soils in the soil-plant-climate system. This discriminated their different abilities in affecting the quality of a wine.

The potential CWSI referred to the last 11 years was very different between the two HZs. The variability expressed by this index for each phenological phases was very high. This was due to the high variability in the weather data used as input for the simulation modelling application.

These important differences between the soil-cropclimate behaviour are mainly due to the different hydrological behaviour, because of the very different hydraulic properties of the soil (see Table 1).
It is essential to notice that the use of simulation models like the one used for this study requires an accurate phase of model calibration and preferably the use of measured data, rather than those estimated by methods (such as pedofunctions) that usually tend to smooth out the soil hydrological properties between otherwise very different soils. This is also the case if the AWC is used as an indicator for crop water availability: the use of pedotransfer functions (PTFs) could produce a clear error, also if the studied soils present similar textures, as reported in Sect. 3.1.

This was our case, where the two soils fell under the same textural class while having very different hydrological behaviour. Hence, the measurement of the hydrological properties was of primary importance in differentiating the two environments.

The behaviour of each soil-plant and atmosphere system (CAL and CAM) was investigated in depth, making the conclusion about their different ability to produce crop water stress very solid. Thus, it was possible to identify two fHZs, corresponding to the previous HZs.

The CAL fHZ represents a system where the Aglianico is subjected to a water stress that is twice as strong as that occurring in the Cambisol fHZ, with a progressive differentiation from flowering to harvesting.

This is clearly in agreement with the water stress felt by plants during the 3 years of monitoring (average $22 \%$ of LWP increase in the CAL). In addition, the Pearson's $r$ of CWSI estimated by the model and by the LWP measured onfield was -0.98 . Moreover, the different behaviour described by the potential CWSI was also confirmed by other plant physiological measurements, including (i) stomatal conductance (the plants in CAL experienced lower values, and thus lower transpiration rates, than those of CAM); (ii) assimilation of $\mathrm{CO}_{2}$ rates (in CAM the plants had more pronounced photosynthetic activity than those of CAL); and (iii) the quantum yield of photosystem PSII in leaves adapted to light (PHIPSII) (plants in CAM were more efficient than CAL plants at capturing the light energy absorbed by the photosystem PSII).

From the enological viewpoint, grapes analysed in this study showed important differences. In CAL fHZ, the grapes were richer in sugars, anthocyanins and total polyphenols and had a lower content of total acids. Considering that Aglianico wines, as traditionally produced, are generally rather acidic, astringent and they easily lose the red colour hue (Gambuti et al., 2007), these data clearly suggest that grapes on CAL $\mathrm{fHZ}$ can produce wine with a more balanced taste that is more alcoholic and less acidic.

Grapes from CAL fHZ showed a higher extractable polyphenol content than those from CAM fHZ, indicating that a more aged wine can be obtained from this part of the vineyard. On the basis of grape sugar content, wines obtained from this fHZ should be also characterized by a higher content of ethanol $(13.5 \% v / v$ with respect to $12 \% v / v$ for CAM fHZ wines) and should show a more intense colour 
because of the content of native pigments (anthocyanins) extracted from skins and their colour intensity. In contrast, CAM fHZ berries showed a lower content of total anthocyanins extracted from skins and a similar content of total polyphenols and tannins extracted from seeds. Taking into account the facts that (i) anthocyanins are mainly extracted during the first phases of red vinification (consisting in the maceration of whole berries during must fermentation), (ii) complete extraction from the seeds requires the berry skins and seeds to be in contact for a longer time with must-wine, and (iii) seed tannins are more astringent than skin tannins (Gambuti et al., 2006), these data suggest that a specific winemaking procedure, such as short maceration, could help obtain a red wine from CAM fHZ grapes with a good colour intensity which is not astringent and which is easier to drink.

Therefore, the enological potentials of grapes from the two sites are very different. By applying the proper winemaking procedure, it is possible to obtain a more ready-to-drink wine from the CAM fHZ site and a long-ageing wine from the CAL fHZ site.

In conclusion, the use of a model output is a useful approach for evaluating and comparing the effects of the CWS in vines induced by soils.

Nevertheless, important prerequisites that should be considered are (i) model calibration (if previous data are available to calibrate it), (ii) preferably measured data, (iii) same plant cultivar, and (iv) same climatic and plant management conditions. This was our case, built up to investigate and compare the "soil suitability to grape production", limiting the effects of other environmental variables. This comparison would not have been feasible with different cultivars (each of which responds differently to water stress) or different boundary conditions.

Moreover, our approach could be improved towards precision farming considering the soil spatial variability in each fHZ in the modelling application, thereby also providing information about the uncertainty of model predictions. However, the use of the latter approach is strictly limited by the availability of spatially distributed soil information needed to apply the simulation model (vertical and horizontal information, e.g. soil horizon depth and thickness and their hydraulic properties).

However, the great potential of the dynamic simulation models applied in this context can be seen. In fact, once the characteristics and parameters of the different SPA systems (i.e. LAI, climate data, cultivar relation between CWSI and quality must parameters) are known, it is potentially possible to estimate, as done in this work, what the plant responses to water stress could be and therefore its effects in must and wine quality, in any soil-plant combination or in any boundary condition, including plant responses to future climate changes. This could have imaginable positive effects on future land use and management planning, for instance the choice of the most suitable plant varieties for specific production targets or the opportunity to apply drip irrigation systems in order to control the plant water status with the aim of improving quality or maintaining the current level. This concept is very similar to the approach reported in the literature for other crops between the yield response and water stress (or water deficit) (see Menenti et al., 2014, or Monaco et al., 2014).

Finally, the GIS analysis of high-resolution DTM and DSM showed that differences in terms of slope and elevation between the two identified fHZs, at vineyard scale, were low and not very important. On the other hand, the aspect and the potential insolation calculated over the cropping season (1 April to 15 October) showed that in the CAM fHZ the plants receive $7 \%$ or more total potential insolation during the cropping season compared to those cultivated in the CAL fHZ. This condition strengthens our results and confirms the hypothesis that, for the scale of our work, soil drives the Aglianico plant expression in terms of must quality and thus wine quality.

\section{Conclusions}

The procedures adopted for viticulture microzoning, including (i) standard large-scale soil mapping, (ii) geophysical mapping and (iii) soil-plant water stress evaluation on the identified fHZs, have shown their robustness in terms of their effects on plant, grape, must and wine quality.

The inclusion of the soil-plant water stress evaluation was fundamental because plant water status affects the characteristics of the grape must, skin and seeds of the Aglianico vine.

In particular the study has shown (i) the importance of the hydropedology approach in knowing the soil properties in order to arrive at a complete characterization of the different pedo-environments (also recognizable at field scale) aimed at viticultural zoning, equal to the well-recognized importance for soil chemical properties; (ii) the link between must characteristics and soil characteristics, particularly CWSI estimated using a simulation model - this can be considered as preliminary information for zoning and planning the vineyard plant (e.g without having local data for calibrating and validating the model); (iii) the need to transform the soil map into a functional map in the viticultural zoning procedures, where the soils are evaluated dynamically on the basis of soil-plant and atmosphere system behaviour (e.g. soil water balance), with the definition of functional homogeneous zones (fHZs) for the vine; and (iv) the potentiality of this approach to explore future prospects in terms of more effective grape variety selection and precision irrigation application to overcome the high CWSI values expected from climate change. 
Acknowledgements. We acknowledge A. Erbaggio, P. Caputo and A. Delle Cave for the field measurements and N. Orefice for soil hydraulic properties measurements. The present work was carried out within the ZOVISA project (PSR Campania 2007-2013, measure 124 , no. 603 of $15 / 10 / 2010$ ).

Edited by: E. Vaudour

\section{References}

Acevedo-Opazo, C. and Ortega-Farias, S.: Effects of grapevine (Vitis vinifera L.) water status on water consumption, vegetative growth and grape quality: An irrigation scheduling application to achieve regulated deficit irrigation, Agr. Water Manage., 97, 956-964, 2010.

Andrenelli, M. C., Costantini, E. A. C., Pellegrini, S., Perria, R., and Vignozzi, N.: On-the-go resistivity sensors employment to support soil survey for precision viticulture, in: Proceedings in VIII International Terroir Congress, Soave, Italy, 14-18 June 2010, 120-125, 2010.

Basile, A., Buttafuoco, G., Mele, G., and Tedeschi, A. : Complementary techniques to assess physical properties of a fine soil irrigated with saline water, Environ. Earth Sci., 66, 1797-1807, 2012.

Ben-Asher, J., van Dam, J., Feddes, R. A., and Jhorar, R. K.: Irrigation of grapevines with saline water II. Mathematical simulation of vine growth and yield, Agr. Water Manage., 83, 22-29, 2006.

Bonfante, A., Basile, A., Acutis, M., De Mascellis, R., Manna, P., Perego, A., and Terribile, F.: SWAP, CropSyst and MACRO comparison in two contrasting soils cropped with maize in Northern Italy, Agr. Water Manage., Elsevier, 97, 1051-1062, 2010.

Bonfante, A., Basile, A., Langella, G., Manna, P., and Terribile, F.: A physically oriented approach to analysis and mapping of terroirs, Geoderma, 167-168, 103-117, 2011.

Brousset, J., Picque, D., Guerin, L., Goulet, E., and Perrot, N.: Potentiel des sols viticoles et qualité des vins, in: Proceedings in VIII International Terroir Congress, Soave, Italy, 14-18 June 2010, 96-101, 2010.

Carey, V. A.: Spatial characterisation of natural terroir units for viticulture in the Bottelaryberg-Simonsberg-Helderberg winegrowing area, MSc Agric Thesis, University of Stellenbosch, 90 pp. + annexes, 2001.

Chapman, D. M., Roby, G., Ebeler, S. E., Guinard, J. X., and Matthews, M. A.: Sensory attributes of Cabernet Sauvignon wines made from vines with different water status, Aust. J. Grape Wine R., 11, 339-347, 2005.

Colombo, C. and Miano, T. (Eds.): Metodi di analisi chimica del suolo - 3 edizione, ISBN 978-88-940679-0-3, Pubblicità \& Stampa, Modugno (BA), Italy, 2015.

Cousin, I., Besson, A., Bourennane, H., Pasquier, C., Nicoullaud, B., King, D., and Richard, G.: From spatial-continuous electrical resistivity measurements to the soil hydraulic functioning at the field scale, C. R. Geosci., 341, 859-867, 2009.

Crescimanno, G. and Garofalo, P.: Application and evaluation of the SWAP model for simulating water and solute transport in a cracking clay soil, Soil Sci. Soc. Am. J., 69, 1943-1954, 2005.

Davies, R.: Mapping soil properties for irrigation development in the River land of south Australia using EM38, in: Proc. 3rd Aus- tralian and New Zeland Soils Conf., SuperSoil 2004, University of Sydney, Australia, CD-Rom, 2004.

Deloire, A., Vaudour, E., Carey, V., Bonnardot, V., and Van Leeuwen, C.: Grapevine responses to terroir: a global approach, J. Int. Sci. Vigne Vin., 39, 149-162, 2005.

Doolittle, J., Petersen, M., and Wheeler, T.: Comparison of two electromagnetic induction tools in salinity appraisals, J. Soil Water Conserv., 56, 257-262, 2001.

Eitzinger, J., Trnka, M., Hösch, J., Žalud, Z., and Dubrovský, M.: Comparison of CERES, WOFOST and SWAP models in simulating soil water content during growing season under different soil conditions, Ecol. Model., 171, 223-246, 2004.

Failla, O., Mariani, L., Bracadoro, L., Minelli, R., Scienza, A., Murada, G., and Mancini, S.: Spatial distribution of solar radiation and its effect on vine phenology and grape ripening in an Alpine environment, Am. J. Enol. Viticult., 55, 128-138, 2004.

FAO: World Reference Base for Soil Resources: A framework for international classification, correlation and communication, World Soil Resources Reports, 103, FAO, Rome, Italy, 2006.

FAO: World Reference Base for Soil Resources: International soil classification system for naming soils and creating legends for soil maps, World Soil Resources Reports, 106, FAO, Rome, Italy, 2014.

Feddes, R. A., Kowalik, P. J., and Zaradny, H.: Simulation of field water use and crop yield, Simul. Monogr. PUDOC, Wageningen, the Netherlands, 1978.

Fregoni, M.: Viticoltura di Qualità, Informatore Agrario, 23/E37133, Verona, Italy, 1988.

Gambuti, A., Rinaldi, A., Pessina, R., and Moio, L.: Evaluation of aglianico grape skin and seed polyphenol astringency by SDSPAGE electrophoresis of salivary proteins after the binding reaction, Food Chem., 97, 614-620, 2006.

Gambuti, A., Strollo, D., Erbaggio, A., Lecce, L., and Moio, L.: Effect of winemaking practices on color indexes and selected bioactive phenolics of Aglianico wine, J. Food Sci., 72, 623-628, 2007.

Genty, B., Briantais, J. M., and Baker, N. R.: The relationship between the quantum yield of photosynthetic electron transport and quenching of chlorophyll fluorescence, Biochim. Biophys. Acta 990, 87-92, 1989.

Girard, M. C. and Girard, C. M.: Processing of remote sensing data, Balkema publishers, Rotterdam, the Netherlands, 2003.

Gladstones, J. and Smart, R. E.: Terroir, in: The Oxford companion to wine, edited by: Robinson, J., Am. J. Enol. Viticult., 38, 211 215, 1997.

Glories, Y.: La couleur des vins rouges, $1^{\circ}$ e $2^{\circ}$ partie, Conn. Vigne Vin., 18, 253-271, 1984.

Heathman, G. C., Starks, P. J., Ahuja, L. R., and Jackson, T. J.: Assimilation of surface soil moisture to estimate profile soil water content, J. Hydrol., 279, 1-17, 2003.

Intrigliolo, D. S. and Castel, J. R.: Interactive effects of deficit irrigation and shoot and cluster thinning on grapevine cv. Tempranillo. Water relations, vine performance and berry and wine composition, Irrigation Sci., 29, 443-454, 2011.

Kozak, J. A., Liwang, Ahuja, L. R., Flerchinger, G., and Nielsen., C. D.: Evaluating varius water stress calculations in RZWQM and RZ-SHAW for corn and soybean production, Agron. J., 98, 1146-1155. 2006. 
Kroes, J. G., van Dam, J. C., Groenendijk, P., Hendriks, R. F. A., and Jacobs, C. M. J.: SWAP version 3.2. Theory description and user manual, Alterra-report 1649, 262 pp., Alterra, Research Institute, Wageningen, the Netherlands, 2008.

Loague, K., and Green, R. E.: Statistical and graphical methods for evaluating solute transport models: overview and application, J. Contam. Hydrol., 7, 51-73, 1991.

Lück E., Gebbers, R., Ruehlmann, J., and Spangenberg, U.: Electrical conductivity mapping for precision farming, Near Surf. Geophys., 7, 15-25, 2009.

Matthews, M. A., Ishii, R., Anderson, M. M., and O'Mahony, M.: Dependence of wine sensory attributes on wine water status, J. Sci. Food Agr., 51, 321-335, 1990.

Mattivi, F., Prast, A., Nicolini, G., and Valenti, L.: Validazione di un nuovo metodo per la misura del potenziale polifenolico delle uve rosse e discussione del suo campo di applicazione in enologia, Riv. Vitic. Enol., 2-3, 55-74, 2002.

Menenti, M., Alfieri, S. M., Bonfante, A., Riccardi, M., Basile, A., Monaco, E., De Michele, C., and De Lorenzi, F.: Adaptation of Irrigated and Rainfed Agriculture to Climate Change: The Vulnerability of Production Systems and the Potential of Intraspecific Biodiversity (Case Studies in Italy), in: Handbook of Climate Change Adaptation, Springer-Verlag, Berlin, Heidelberg, doi:10.1007/978-3-642-40455-9_54-1, 2014.

Mertens, J., Madsen, H., and Kristensen, M.: Sensitivity of soil parameters in unsaturated zone modelling and the relation between effective, laboratory and in situ estimates, Hydrol. Process., 19, 1611-1633, 2005.

Minacapilli, M., Agnese, C., Blanda, F., Cammalleri, C., Ciraolo, G., D’Urso, G., Iovino, M., Pumo, D., Provenzano, G., and Rallo, G.: Estimation of actual evapotranspiration of Mediterranean perennial crops by means of remote-sensing based surface energy balance models, Hydrol. Earth Syst. Sci., 13, 1061-1074, doi:10.5194/hess-13-1061-2009, 2009.

Monaco, E., Bonfante, A., Alfieri, S. M., Basile, A., Menenti, M., and De Lorenzi, F.: Climate change, effective water use for irrigation and adaptability of maize: A case study in southern Italy, Biosys. Eng., 128, 82-99, 2014.

Morari, F., Castrignanò, A., and Pagliarin, C.: Application of multivariate geostatistics in delineating management zones within a gravelly vineyard using geo-electrical sensors, Comput. Electron. Agric., 68, 97-107, 2009.

Mualem, Y.: A new model for predicting the hydraulic conductivity of unsaturated porous media, Water Resour. Res., 12, 513-522, 1976.

OIV: Compendium of International Methods of Wine and Must Analysis, Office International de la Vigneet du Vin, Paris, France, 2007.

Ojeda, H., Andary, C., Kraeva, E., Carbonneau, A., and Deloire, A.: Influence of pre-and postveraison water deficit on synthesis and concentration of skin phenolic compounds during berry growth of Vitis vinifera cv. Shiraz, Am. J. Enol. Viticult., 53, 261-267, 2002.

Priori, S., Costantini, E. A. C., Agnelli, A., Pellegrini, S., and Martini, E.: Three proximal sensors to estimate texture, skeleton and soil water storage in vineyards, in: Proceedings in VIII International Terroir Congress, Soave, Italy, 14-18 June 2010, 38-43, 2010 .
Priori, S., Martini, E., Andrenelli, M. C., Magini, S., Agnelli, A.E., Bucelli, P., Biagi, M., Pellegrini, S., and Costantini, E. A. C.: Improving Wine Quality through Harvest Zoning and Combined Use of Remote and Soil Proximal Sensing, Soil Sci. Soc. Am. J., 77, 1338-1348, 2012.

Rallo, G., Agnese, C., Minacapilli, M., and Provenzano, G.: Comparison of SWAP and FAO Agro-Hydrological Models to Schedule Irrigation of Wine Grapes, J. Irrig. Drain Eng., 138, 581-591, 2012.

Reynolds, W. D., Elrick, D. E., Youngs, E. G., Amoozegar, A., Booltink, H. W. G., and Bouma, J.: Saturated and field-saturated water flow parameters, in: Methods of soil analysis, edited by: Dane, J. H. and Topp, G. C., Part 4, Physical methods, 797-878, Madison, Wi, USA, Soil Sci. Soc. Am. J., 2002.

Ribereau-Gayon, P. and Stonestreet, E.: Le dosage des anthocyanesdans les vins rouges, Bull. Soc. Chim, 9, 2649-2652, 1965.

Ribereau-Gayon, P. and Stonestreet, E.: Le dosage des tanins du vin rouge et la determination de leur structure, Chimie Anal., 48, 188-192, 1966.

Ritchie, J. T.: Model for predicting evaporation from a row crop with incomplete cover, Water Resour. Res., 8, 1204-1213, 1972.

Romero, P., Gil-Muñoz, R., del Amor, F. M., and Valdés, E.: Regulated deficit irrigation based upon optimum water status improves phenolic composition in Monastrell grapes and wines, Agr. Water Manage., 121, 85-101, 2013.

Saey, T., Simpson, D., Vermeersch, H., Cockx, L., and Van Meirvenne, M.: Comparing the EM38-DD and Dualem-21S sensors to depth-to-clay mapping, Soil Sci. Soc. Am. J., 73, 7-12, 2009.

Samouëlian, A., Cousin, I., Tabbagh, A., Bruand, A., and Richard, G.: Electrical resistivity survey in soil science: a review, Soil Tillage Res., 83, 173-193, 2005.

Sheikh, V. and van Loon, E. E.: Comparing performance and parameterization of a one-dimensional unsaturated zone model across scales, Vadose Zone J., 6, 638-650, 2007.

Singh, R.: Water productivity analysis from field to regional scale: integration of crop and soil modelling, remote sensing and geographical information, PhD Diss. Wageningen Univ., Wageningen, the Netherlands, 2005.

Taylor, S. T. and Ashcroft, G. L.: Physical edaphology: The physics of irrigated and non-irrigated soils, edited by: Freeman, W. H., San Francisco, CA, USA, 1972.

Tromp-van Meerveld, H. J. and McDonnell, J. J.: Assessment of multi-frequency electromagnetic induction for determining soil moisture patterns at hillslope scale, J. Hydrol., 368, 56-67, 2009.

Vacca, V., Del Caro, A., Millela, G. G., and Nieddu, G.: Preliminary characterisation of Sardinian red grape cultivars (Vitisvinifera L.) according to their phenolic potential, S. Afr. J. Enol. Vitic., 30, 93-100, 2009.

Van Genuchten, M. Th.: A closed form equation for predicting the hydraulic conductivity of unsaturated soils, Soil Sci. Soc. Am. J., 44, 892-898, 1980.

Van Leeuwen, C., Tregoat, O., Choné, X., Bois, B., Pernet, D., and Gaudillère, J.-P.: Vine water status is a key factor in grape ripening and vintage quality for red Bordeaux wine. How can it be assessed for vineyard management purposes, J. Int. Sci. Vigne Vin, 43. 121-134, 2009.

Vaudour, E.: Les terroirs viticoles. Analyse spatial et relation avec la qualité du raisin, Application au vignoble AOC des 
Côtes-du-Rhône méridionales, Thèse dedoctorat, Istitut national agronomique Paris-Grignon, Paris, France, 2001.

Vaudour, E.: Les terroirs viticoles, Definitions, caractérisation et protection, Dunod, Paris, France, 2003.

Vaudour, E. and Shaw, A. B.: A Worldwide Perspective on Viticultural Zoning, S. Afr. J. Enol. Vitic., 26, 106-115, 2005.

Vaudour, E., Carey V. A., and Gilliot, J. M.: Digital zoning of South African viticultural terroirs using bootstrapped decision trees on morphometric data and multitemporal SPOT images, Remote Sens. Environ., 114, 2940-2950, 2010. von Caemmerer, S. and Farquhar, G. D.: Some relationships between the biochemistry of photosynthesis and the gas exchange of leaves, Planta, 153, 376-387, 1981.

Wegehenkel, M.: Validation of a soil water balance model using soil water content and pressure head data, Hydrol. Process., 19, 1139-1164, 2005. 